\title{
Formation and Properties of Responsive Siloxane-Based Polymeric Surfaces with Tunable Surface Reconstruction Kinetics
}

\author{
By Julie Ann Crowe-Willoughby* and Jan Genzer*
}

Here, the formation of responsive polymeric materials with tunable response time is reported. These structures are fabricated by chemically modifying poly(vinylmethyl siloxane) (PVMS) networks with alkanethiols bearing a hydrophilic end-group $(-\mathrm{COOH}$ or $-\mathrm{OH})$. The response time is facilitated by the liquid nature of the PVMS backbone and increases with increase in length of the methylene spacer $\left(-\mathrm{CH}_{2}\right)_{n}$ - in the alkanethiol pendent group. While for $n=\mathbf{2}$ and $\mathbf{6}$, the surface reconstructs almost instantaneously, specimens with $n=11$ resist reconstruction because of strong van der Waals forces, leading to the formation of semi-crystalline regions. It is demonstrated that the responsive nature of PVMS-S- $\left(\mathrm{CH}_{2}\right)_{11} \mathrm{OH}$ can be fine-tuned by varying the temperature; it possesses a faster response at temperatures above the melting point of the $-\mathrm{S}-\left(\mathrm{CH}_{2}\right)_{11} \mathrm{OH}$ moiety.

\section{Introduction}

A responsive surface adapts its physico-chemical characteristics in response to an external stimulus, be it chemical, electrical, or mechanical. ${ }^{[1-6]}$ It can entail a recognition event that triggers a conditional response. Consider, for instance, a pH-responsive polymer conjugated with glucose oxidase and embedded with insulin. When sufficient levels of glucose are present in the contacting media, a decrease in the $\mathrm{pH}$ causes a matrix pore-size change due to polymer collapse, thereby releasing insulin. ${ }^{[7]}$ Such materials are often described as biomimetic ${ }^{[4]}$ due to their ability to mimic the efficient conversion of chemical energy into mechanical energy in living organisms and their use has been demonstrated in artificial muscles. ${ }^{[7]}$ In many cases, surface responsiveness results from the rearrangement of various chemical functionalities present close to or directly at the surface. The two key parameters that define the functionality (and ultimately application) of any responsive surface are i) the degree of change of the surface properties after the external trigger was applied and ii) the rate at which these variations occur. Hence an

[*] Dr. J. A. Crowe-Willoughby, ${ }^{[+]}$Prof. J. Genzer

Department of Chemical and Biomolecular Engineering

North Carolina State University

Raleigh, NC 27695-7905 (USA)

E-mail: julie.willoughby@gmail.com; Jan_Genzer@ncsu.edu

$\left[{ }^{+}\right]$Present address: MeadWestVako, Center for Packaging Innovation, 1021 Main Campus Drive, Raleigh, NC 27606, USA

DOI: 10.1002/adfm.200800622 "ultimate" responsive surface is one that instantaneously responds to changes in its environment with a measurable property change. Defining the optimum response of a switchable surface involves understanding the characteristics responsible for the change in surface properties. Creating a surface that turns on or off within an optimum timeframe first requires a measurable magnitude change in response to environmental changes such as temperature, $\mathrm{pH}$, or chemical composition. In addition, the reversibility of a true switchable surface should not deteriorate over time.

Polymers offer a convenient material platform for generating responsive surfaces. The mobility of the backbone (and hence the response time) can be adjusted by varying the application temperature relative to the polymer's glass transition temperature, $T_{\mathrm{g}}$. Additional tunability can be achieved by confinement; recent results have shown that the $T_{\mathrm{g}}$ is lower in the surface region than in the bulk enhancing surface reconstruction rates. ${ }^{[8-10]}$ In addition, polymers can be readily chemically functionalized, which could encompass attaching hydrophobic, hydrophilic, or specific recognition receptor moieties. Overall, it is the combination of the solid-liquid duality due to $T_{\mathrm{g}}$ and local molecular heterogeneities along the polymer backbone that provide convenient means of tuning the response time of polymeric materials to changes in the environment.

The dynamic nature of polymer surfaces, reconstruction dynamics associated with switching the external medium, and changing the chemical make-up of the surface itself has been studied by several research groups in the past. Early on, Whitesides and coworkers evaluated the wettability of oxidized polyethylene after various environmental exposures and temperature variations. ${ }^{[11]}$ Koberstein reported on the responsivness of synthetic polymeric systems equipped with various end-groups ranging from hydrophilic (i.e., carboxylic acid) to hydrophobic (i.e., various fluorine-containing moieties). ${ }^{[12]}$ By varying substrate elasticity and composition of oxidized butadienes to create a system with a controlled rate of surface reconstruction, Ferguson and coworkers argued that surface reconstruction was dictated by shifts in enthalpic and entropic driving forces on the surface free energy. ${ }^{[13-15]}$

Surface reconstruction is also associated with surface segregation of polymers and their reorientation at the surface. 
These two modes often act in accord and contribute simultaneously to variations in surface activity. First, polymer mobility in the bulk and at the surface depends on system temperature. While polymer motion in a glassy state is very slow, it increases dramatically when the temperature of the system is raised above $T_{\mathrm{g}}$. At temperatures above $T_{\mathrm{g}}$ the polymer chains can restore their preferred random flight conformations if an entropic gain exceeds enthalpic interactions between the polymer and the surface, unless there is an additional constraint, such as the presence of crystalline or cross-linked regions. There are applications where surface stability is desired. For instance, Genzer and Efimenko implemented a mechanically assisted monolayers (MAMs) technique to manipulate the packing density of hydrophobic molecules attached chemically to poly(dimethyl siloxane) (PDMS) networks hydrophilicized with a brief exposure to ultraviolet/ozone treatment. ${ }^{[16]}$ By performing the surface modification under strained conditions, fluorinated alkane silanes had sufficient space to orient perpendicular to the surface. Upon release of the strain, these molecules were "squeezed" into a dense alignment preventing chain reorientation. Rouse et al.'s work on "frustrated" glassy surfaces also accentuated entropic control at a polymer interface by manipulating the reconstruction temperature. ${ }^{[17]}$ Using poly(4-methyl styrene) as a model glassy polymer, Rouse et al. oxidized its surface below the polymer's $T_{\mathrm{g}}$ of $110^{\circ} \mathrm{C}$. The resulting functionalized surface was "locked" and remained hydrophilic when exposed to air below its bulk $T_{\mathrm{g}}$.

A direct correlation exists between polymer elasticity and surface response. Starting with a very flexible substrate, such as a silicone elastomer, one increases the likelihood of generating prompt responses to external stimuli. Relatively inert PDMS does not lend itself to a dual-characteristic surface. However, replacing one of the methyl groups in PDMS with another chemical moiety, such as vinyl in the case of poly(vinylmethyl siloxane) (PVMS), increases chemical tailorability. PVMS is a unique polymer providing multiple functions: i) the low surface energy methyl group, ii) the highly flexible siloxane backbone, and iii) the vinyl moiety that can be used as an attachment point for various chemistries. We incorporated this design flexibility into our research by i) synthesizing various molecular weight PVMS with reactive end-groups for subsequent network formation, ii) utilizing alkoxy-condensation cure chemistry for network formation that would allow us to later react the vinyl moieties, and iii) modifying PVMS with hydrophilic and hydrophobic functionalities.

Our initial observations of reversible PVMS siloxane surfaces was demonstrated with deionized (DI) water contact angle ( $\left.\theta_{\text {DIW }}\right)$ measurements. ${ }^{[18]}$ As the vinyl group has a slightly higher surface energy than the methyl group, it hides beneath the surface when exposed to hydrophobic environments, such as air. Exposure to water leads to a rearrangement of the surface moiety makeup as the preferred state is orientation of the vinyl groups at the surface. As contact angle measurements are sensitive to just the first $\sim 5 \AA$ of the polymer surface, ${ }^{[19]}$ the composition rearrangement can be observed by time-dependent contact angle measurements and utilized to characterize response kinetics of modified and unmodified PDMS and PVMS surfaces. We have shown previously ${ }^{[20]}$ that the rate of change of contact angle with time $\left(\mathrm{d} \theta_{\text {DIW }} / \mathrm{d} t\right)$ of water exposure time was found to be constant for
PDMS networks. In contrast, the PVMS data indicated the existence of two wettability regions: i) as water comes into contact with the PVMS surface, the system minimizes its free energy by replacing the hydrophobic methyl groups with higher-surface energy vinyl moieties at the PVMS/water interface and ii) the rapid decrease in the contact angle recorded at the short exposure times can thus be associated with the aforementioned rearrangements of the functionalities on the surface. While the rapid rate of the PVMS response is a consequence of the high flexibility of the $\mathrm{Si}-\mathrm{O}$ backbone, the surface energy difference between the methyl and vinyl substituents is small. To further accentuate the difference in surface energy effects, we modified the vinyl moiety on the PVMS substrate through a thiolene addition reaction. ${ }^{[21]}$ Utilizing this surface modification technique enables the introduction of siloxane networks as a novel platform of substrates capable of rapidly reorganizing in the presence of polar media.

In this paper, we build on the responsive nature of PVMS surfaces by grafting amphiphilic moieties on the silicone elastomer backbone. Specifically, we provide evidence that the combination of the high flexibility of the silicone elastomer chain and the amphiphilic nature of the side groups endows these materials with exceptionally fast surface reconstruction kinetics and a high degree of repeatability. Moreover, we show that additional control over the molecular arrangement on such substrates can be achieved when the amphiphilic moieties attached to the PVMS backbone can locally crystallize.

\section{Results and Discussion}

\subsection{Modified PVMS Surfaces}

Implementing the thiol-ene addition reaction on PVMS networks, a route others demonstrated with fluid polymers, ${ }^{[15,22-24]}$ we modified PVMS substrates with 11-dodecanethiol $\left(\mathrm{HS}\left(\mathrm{CH}_{2}\right)_{11} \mathrm{CH}_{3}\right)$ and 3-mercaptopropionic acid $\left(\mathrm{HS}\left(\mathrm{CH}_{2}\right)_{2} \mathrm{COOH}\right)$. The addition to the vinyl bond was confirmed via the elimination of the $\mathrm{C}=\mathrm{C}$ peaks at 960,1407 , and $1587 \mathrm{~cm}^{-1}$ in Fourier transform infrared spectroscopy in the attenuated total reflection mode (FTIR-ATR). In Figure 1, we plot the FTIR-ATR data for the 11-dodecanethiol addition to PVMS. The results indicate a high yield of attachment of the alkane groups; the peaks corresponding to the vinyl group in the modified samples were absent after the thiol-ene reaction. The surface composition variation in thiol-ene modified-PVMS samples was also confirmed by a change in the water contact angle. The dodecane group is more hydrophobic than the methyl group, as is apparent in the water contact angle shift of $\sim 105^{\circ}$ before modification to $\sim 125^{\circ}$ after modification (Fig. 1). Note that the thiol-ene reaction with 11-dodecanethiol took place in the bulk siloxane fluid. This modified PVMS fluid was subsequently crosslinked through its hydroxyl endgroups. The high water contact angle $\left(\sim 125^{\circ}\right)$ of the PVMS-S- $\left(\mathrm{CH}_{2}\right)_{11} \mathrm{CH}_{3}$ substrate is likely due to both the hydrophobicity of 11-dodecanethiol and the inherent roughness of cross-linking such a heavy substituted siloxane chain.

Obtaining dual-responsiveness of the opposing substituent groups requires a situation as illustrated in Figure 2 for the 


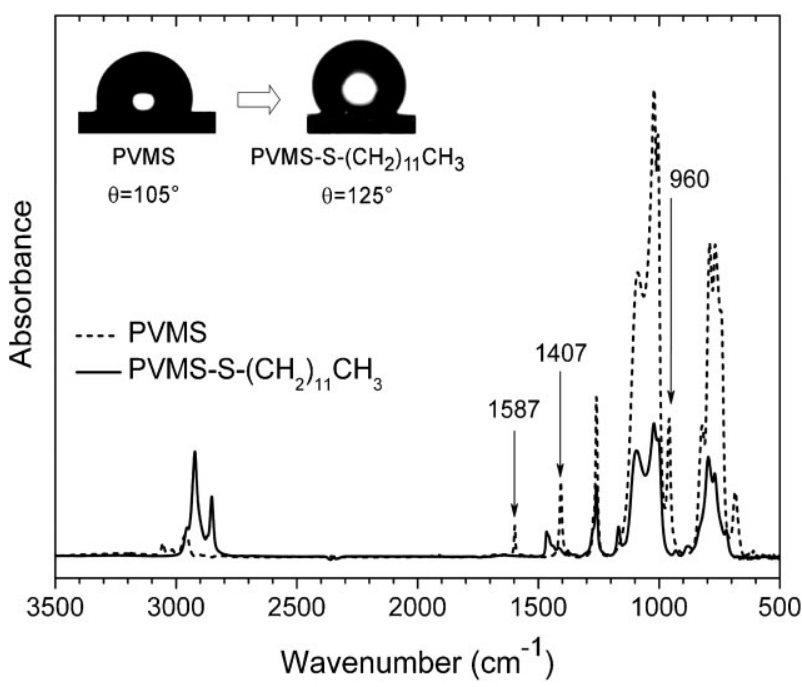

Figure 1. FTIR-ATR spectra of bare PVMS (dashed line) and PVMS after thiol-ene addition of 1-dodecanethiol, PVMS-S- $\left(\mathrm{CH}_{2}\right)_{11} \mathrm{CH}_{3}$ (solid line). The PVMS network was prepared by crosslinking PVMS chains $\left(M_{\mathrm{n}}=\right.$ $39 \mathrm{kDa}$ ) with a $70 \%$ excess of TEOS cross-linker. Vinyl peaks at 960, 1407, and $1587 \mathrm{~cm}^{-1}$ in the thiol-ene modified sample are not present. The inset shows photographs of water droplets on PVMS and PVMS-S- $\left(\mathrm{CH}_{2}\right)_{11} \mathrm{CH}_{3}$ samples.

carboxy- and alkyl-functionalized siloxane substrates. When the surface is exposed to air, the methyl groups populate the substrate/air interface while the carboxy-terminated pendent group resides underneath the surface. Exposing the substrate to water repels the methyl groups from the surface and attracts the carboxy-groups in their stead to maximize the polar interactions. The opposite situation is expected for alkyl-terminated PVMS.

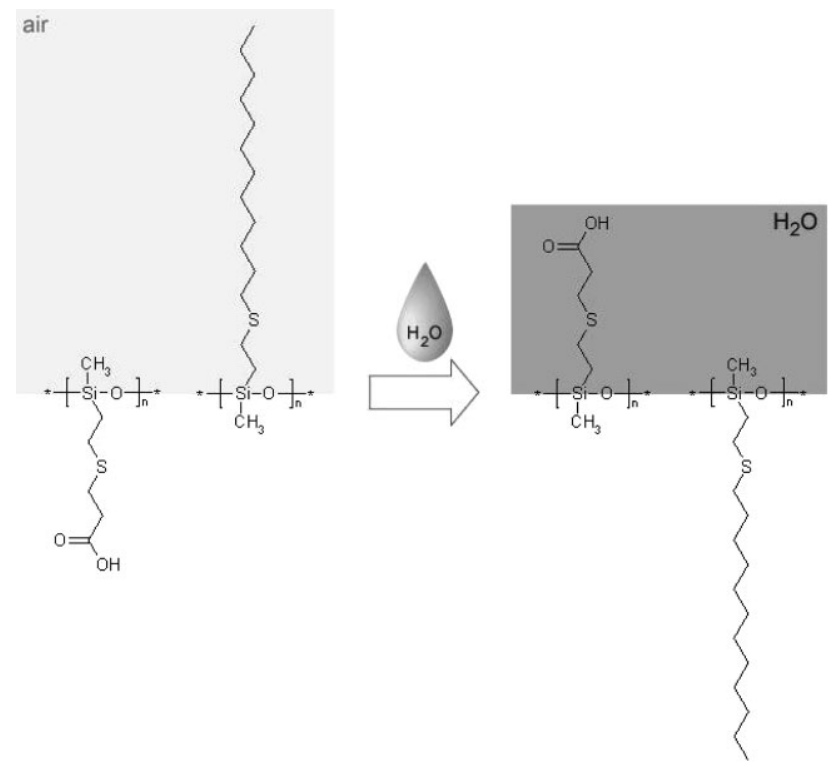

Figure 2. Schematic illustrating the molecular orientation of PVMS modified with 3-mercaptopropionic acid $\left(\mathrm{HS}\left(\mathrm{CH}_{2}\right)_{2} \mathrm{COOH}\right)$ and 11-dodecanethiol $\left(\mathrm{HS}\left(\mathrm{CH}_{2}\right)_{11} \mathrm{CH}_{3}\right)$ at the air/sample and water/sample interfaces.

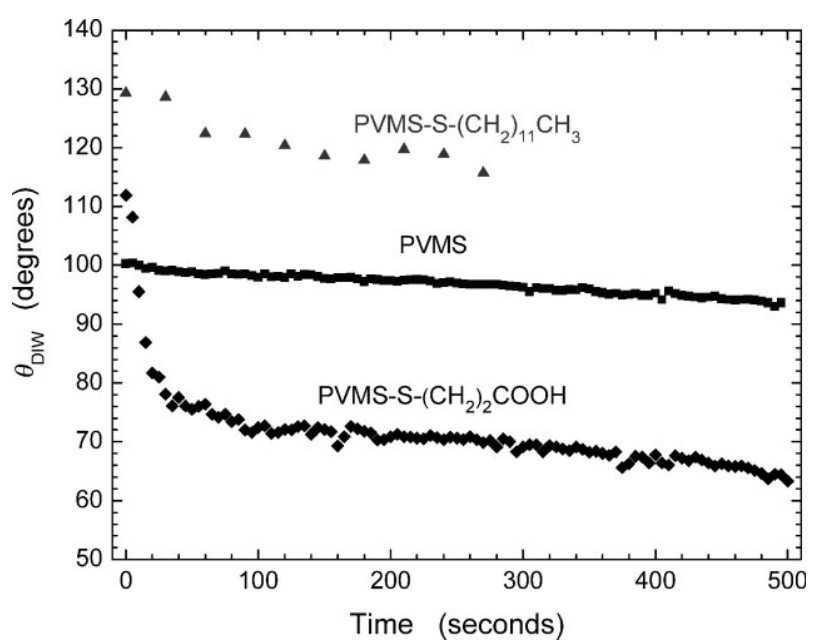

Figure 3. Time-dependent water contact data for PVMS substrates $\left(\bar{M}_{\mathrm{n}}=39 \mathrm{kDa}, R=1.7\right.$ moles of cross-linker/moles of polymer $)$ : bare PVMS

), PVMS-S- $\left(\mathrm{CH}_{2}\right)_{11} \mathrm{CH}_{3}(\mathbf{\Delta})$, and PVMS-S- $\left(\mathrm{CH}_{2}\right)_{2} \mathrm{COOH}(\diamond)$. Average error in contact angle measurement is $\pm 1.5^{\circ}$.

Here alkyls longer than methyl are expected to populate the substrate/air interface but will "hide" beneath the surface when exposed to water, thus allowing the shorter and less hydrophobic methyls to occupy the sample surface. To confirm that the thiolene addition modification resulted in a dual-energy surface, timedependent water contact angle measurements were performed at room temperature for PVMS, PVMS-S- $\left(\mathrm{CH}_{2}\right)_{11} \mathrm{CH}_{3}$, and PVMS-S- $\left(\mathrm{CH}_{2}\right)_{2} \mathrm{COOH}$, as demonstrated in Figure 3. After three minutes of exposure to the probing water droplet, the PVMS-S- $\left(\mathrm{CH}_{2}\right)_{11} \mathrm{CH}_{3}$ substrate became less hydrophobic; the contact angle changed from $\sim 125$ to $\sim 115^{\circ}$. In contrast, the high energy PVMS-S- $\left(\mathrm{CH}_{2}\right)_{2} \mathrm{COOH}$ substrate responded almost instantaneously to water exposure with a $2^{\circ}$ per second drop in contact angle. This ultrafast response has been attributed to both the high flexibility of the polymer backbone and the large chemical disparity between the methyl and carboxylic acid groups.

Surfaces with fast and reversible reconstruction are needed for designing materials with real-time switchable behavior. Other researchers observed that reversibility disappeared after several switching cycles. ${ }^{[14,25-27]}$ In order to return the material to the original surface composition, another stimulus, such as temperature, had to be applied. ${ }^{[11]}$ We postulated that, as barriers to rotation for the siloxane backbone are very low, the PVMS network would easily reorient in a new media to favor the lowest energy state. We observed this behavior during a reversibility study with the PVMS-S- $\left(\mathrm{CH}_{2}\right)_{2} \mathrm{COOH}$ surface in contact with the water droplet (Fig. 4). After the first cycle of rapid surface reorientation, we removed the water droplet via adsorption by a Kim wipe. The surface was dried with a stream of nitrogen and allowed to rest in ambient conditions for 3-5 min. At this point, we applied another water droplet to the same location on the surface. Excellent reversibility was observed (Fig. 4) as the surface was able to return to its original hydrophobic state, indicating that: i) residual water was removed from the surface, as contact angles exceeding $110^{\circ}$ would be difficult to obtain otherwise, ii) the $-\mathrm{S}-\left(\mathrm{CH}_{2}\right)_{2} \mathrm{COOH}$ moieties easily reoriented beneath the 


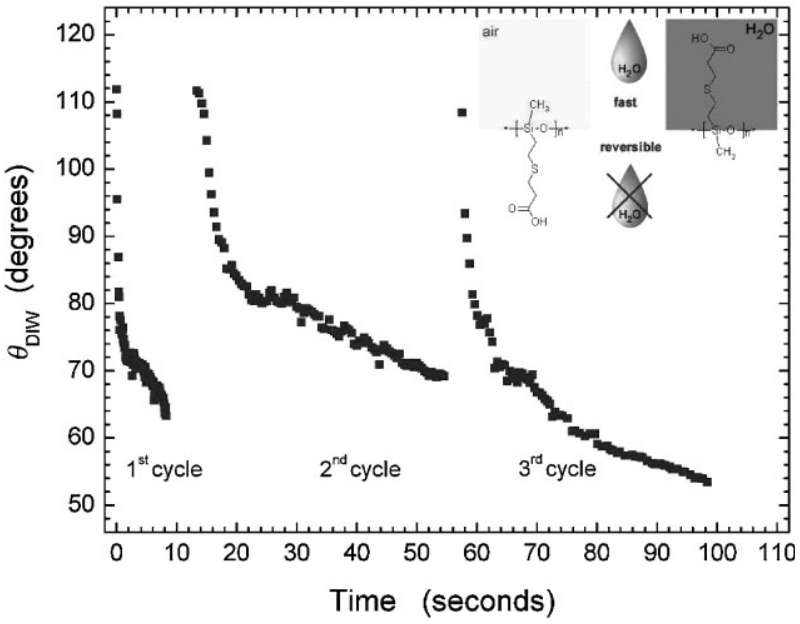

Figure 4. Ability of PVMS-S- $\left(\mathrm{CH}_{2}\right)_{2} \mathrm{COOH}$ to reverse its wettability behavior. The inset shows schematically the conformation of the $-\mathrm{S}-\left(\mathrm{CH}_{2}\right)_{2} \mathrm{COOH}$ linker in response to the variation of the environment.

surface upon removal of the water drop, and iii) returned to the surface when exposed to additional water. The data in Figure 4 indicate that the reversible behavior may be dampening, as the third cycle's starting contact angle was $1-2^{\circ}$ less and ended with the lowest contact angle of the three sets $\left(\sim 55^{\circ}\right)$.

It is instructive to compare the reorientation kinetics detected in our PVMS-based materials to that reported previously for other systems. For example, oxidized polyethylene reoriented only at elevated temperatures due to its high $T_{\mathrm{g}} \cdot{ }^{[11]}$ While it restructured to its hydrophobic state in vacuum at $100{ }^{\circ} \mathrm{C}$ within a few minutes, our PVMS-S- $\left(\mathrm{CH}_{2}\right)_{2} \mathrm{COOH}$ responded in seconds at room temperature. ${ }^{[28]}$ Fluorine-terminated polystyrene exposed to a saturated humid environment decreased $10^{\circ}$ in water contact angle after ten days of contact time. ${ }^{[29]}$ The surface segregation of polyisoprene in PS-b-PI- $\left(\mathrm{CH}_{2}\right)_{3} \mathrm{~N}\left(\mathrm{CH}_{3}\right)_{2}$ occurred after annealing the surface for $24 \mathrm{~h}$ at $170^{\circ}$ (above the $T_{\mathrm{g}}$ ) and the dimethylamine end group reoriented only after 6-10 days of humidity exposure. ${ }^{[30]}$ Oxidized 1,2-polybutadiene took hours to oscillate between hydrophobic and hydrophilic surfaces when relying solely on contacting media effects at room temperature but did respond within minutes to heated water. ${ }^{[15]}$ To our knowledge, the observed reorientation kinetics of PVMS-S- $\left(\mathrm{CH}_{2}\right)_{2} \mathrm{COOH}$ thus possesses the fastest responses ever reported for any polymeric surface.

\subsection{Tailored Wettability Switching Kinetics and Reconstruction Reversibility}

Inspection of the data for the PVMS-S- $\left(\mathrm{CH}_{2}\right){ }_{11} \mathrm{CH}_{3}$ substrate in Figure 3 indicates its loss of hydrophobicity after exposure to water, as the methyl groups have a higher surface energy compared to the 11-dodecanethiol substituents. While the surface reconstruction occurs, it does so at a slower rate than for the PVMS-S- $\left(\mathrm{CH}_{2}\right)_{2} \mathrm{COOH}$ substrate. This behavior can be attributed to the difference in the methylene spacers where a $-\left(\mathrm{CH}_{2}\right)_{11}-$ spacer would be more "sluggish" to rearrange than a shorter
$-\left(\mathrm{CH}_{2}\right)_{2}-$ spacer. In order to comprehend the mechanism of surface rearrangement, we chemically grafted mercaptoalkanols with methylene spacers with a variable length. ${ }^{[21]}$ Evaluating the surface response of mercaptoalkanols versus mercaptoalkanoic acids eliminated any possible complications of acid-base interactions due to the carboxy groups. ${ }^{[1,31,32]}$ As previously, we study the surface rearrangement kinetics by monitoring wettability changes using static contact angle measurements. To further characterize surface reconstruction in the mercaptoalkanol-modified PVMS substrates, we exposed the specimens to alternating wet and dry cycles utilizing dynamic contact-angle measurements to study hysteresis in the surface reorganization. We will demonstrate that an increase in the number of methylene spacers in the mercaptoalkanols leads to slower reorganization kinetics and eventual loss of surface switching due to the tendency of these side groups to form semi-crystalline domains at the surface. ${ }^{[33-35]}$

PVMS sheets were modified with three different mercaptoalkanols: $\mathrm{HS}\left(\mathrm{CH}_{2}\right)_{2} \mathrm{OH}, \mathrm{HS}\left(\mathrm{CH}_{2}\right)_{6} \mathrm{OH}$, and $\mathrm{HS}\left(\mathrm{CH}_{2}\right)_{11} \mathrm{OH}$. In Figure 5 we compare the static contact angle of DI water $\left(\theta_{\text {DIW }}\right)$ as a function of time for each mercaptoalkanol-modified PVMS surface. PVMS-S- $\left(\mathrm{CH}_{2}\right)_{2} \mathrm{OH}$ exhibited a very fast drop in contact angle upon exposure to water $\left(\Delta \theta_{\text {DIW }} \approx 35^{\circ}\right)$. In contrast, PVMS-S- $\left(\mathrm{CH}_{2}\right){ }_{11} \mathrm{OH}$ revealed only a modest change in contact

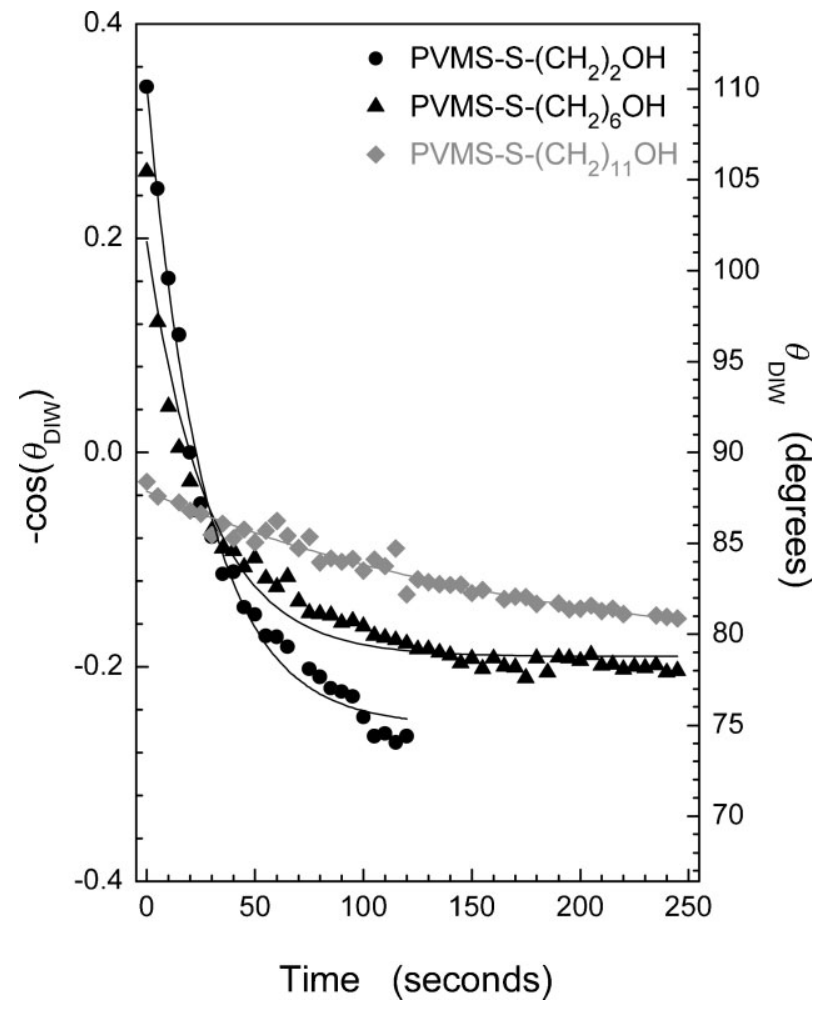

Figure 5. Time dependence of the $\mathrm{DI}$ water wettabilities for PVMS-S- $\left(\mathrm{CH}_{2}\right)_{n} \mathrm{OH}$ surfaces. The error for $\theta_{\text {DIW }}$ is $\pm 1.5^{\circ}$. The lines represent the best fits to $-\cos \left(\theta_{D I W}\right)=A+B e^{-C t}$, where $t$ is time in seconds. The values of $A, B$, and $C$ are: $n=2: A=-0.255, B=0.597$, $C=-0.0375, n=6: A=-0.190, B=0.387, C=-0.0355$, and $n=11$ : $A=-0.198, B=0.162, C=-0.0055$. 
angle $\left(\Delta \theta_{\text {DIW }} \approx 7^{\circ}\right)$. This rather sluggish response of PVMS-S- $\left(\mathrm{CH}_{2}\right)_{11} \mathrm{OH}$ upon exposure to water is attributed to a reduced mobility of surface-bound $-\left(\mathrm{CH}_{2}\right)_{11}$ - side chains due to characteristic semi-crystalline behavior. As we will demonstrate later, this behavior is inferred from a transition from a transparent to an opaque state, ten-fold increase in the storage modulus, differential scanning calorimetry (DSC), and a transition from a liquid-like to a semi-crystalline-like state established by infrared spectroscopy.

While the PVMS-S- $\left(\mathrm{CH}_{2}\right)_{2} \mathrm{OH}$ and PVMS-S- $\left(\mathrm{CH}_{2}\right)_{6} \mathrm{OH}$ surfaces initially displayed fast surface reorientation kinetics after water exposure, it is the repeatability of the cycling behavior between wet and dry states that critically determines the viability of these surfaces as stimuli-responsive materials. In order to evaluate wettability cycling with minimal sample handling we utilized a Cahn dynamic contact analyzer (DCA) using methodology described in the Experimental section. Figure 6 depicts cycling wettabilities measured for unmodified PVMS and PVMS-S- $\left(\mathrm{CH}_{2}\right)_{\mathrm{n}} \mathrm{OH}$; one cycle represents an average of all measurements carried out on three separate specimens. For PVMS, the repeated oscillations displayed only minute changes in surface wettability, in agreement with previous findings. ${ }^{[20,21,28]}$ For PVMS-S- $\left(\mathrm{CH}_{2}\right)_{2} \mathrm{OH}$ and PVMS-S- $\left(\mathrm{CH}_{2}\right)_{6} \mathrm{OH}$, the repeated DCA oscillations demonstrated a close compliance with the static contact angle results. The difference between contact angles of the dry and wet states for PVMS-S- $\left(\mathrm{CH}_{2}\right)_{6} \mathrm{OH}$ was consistent through all cycles with only a slight decrease in starting contact angle. PVMS-S- $\left(\mathrm{CH}_{2}\right)_{2} \mathrm{OH}$ cycles were even more repeatable with little sign of any dampening behavior. This substrate exhibited the largest change in contact angle and

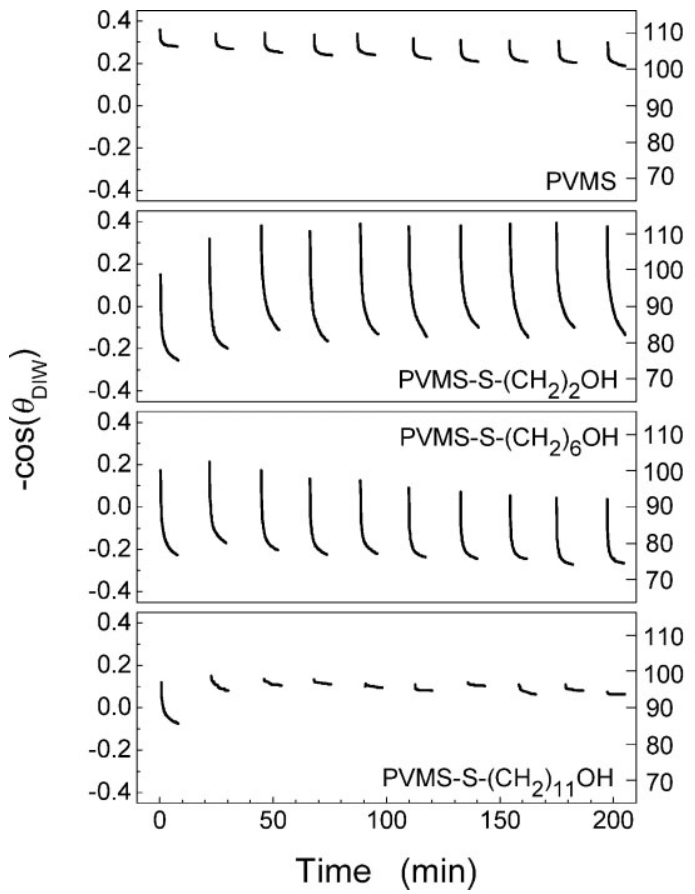

${ }^{\frac{0}{8}}$

Figure 6. Time dependence of the DI water wettabilities for PVMS-S- $\left(\mathrm{CH}_{2}\right)_{n} \mathrm{OH}$ surfaces measured by dynamic contact angle. The error for $\theta_{\text {DIN }}$ is $\pm 1.5^{\circ}$. displayed a greater starting hydrophobic value after the initial cycle. Since this chain possessed the shortest methylene linker, the flexibility of the siloxane backbone remained intact, thus allowing for the restructuring to occur very rapidly between the methyl and 3-mercaptoethanol substituents. The behavior of PVMS-S- $\left(\mathrm{CH}_{2}\right)_{11} \mathrm{OH}$ was more complex, however. While we observed an initial surface reorientation after the first waterdipping cycle, the surface "froze" in the hydrophobic state during all subsequent cycles. We attempted to recover the original hydrophilic response of PVMS-S- $\left(\mathrm{CH}_{2}\right)_{11} \mathrm{OH}$ by exposing the specimens to hot water $\left(95^{\circ} \mathrm{C}\right)$ for $60 \mathrm{~min}$. After the heattreatment, the surface reorientation was frozen by immersion in $25^{\circ} \mathrm{C}$ water and dried with nitrogen. This surface reoriented to a stable, more hydrophilic surface $\left(\theta \approx 80^{\circ}\right)$. Continued monitoring of the specimen revealed a slow reconstruction to the hydrophobic state $\left(\theta \approx 96^{\circ}\right)$ after exposure to air for several days. We note that it was possible to quickly restructure the surface to a starting contact angle of $\sim 105^{\circ}$ if the sample was heated in water and allowed to slowly air cool versus quenching in $25^{\circ} \mathrm{C}$ water. This result is consistent with the findings of Carey et al. ${ }^{[13]}$ and Holmes-Farley et al. ${ }^{[1]}$ for surface restructuring of oxidized polybutadiene and oxidized polyethylene, respectively.

Further information pertaining to chain reorganization on the PVMS surfaces was gathered from monitoring the contact angle hysteresis with the DCA experiments. During the immersion and emersion stages, the advancing and receding contact angles were measured as a function of the exposed substrate. Contact angle hysteresis, defined here as $\theta_{\text {advancing }}-\theta_{\text {receding }}(\Delta \theta)$, is a measure of several factors, including surface roughness, surface homogeneity, sample swelling or liquid penetration, and surface reorientation. ${ }^{[36]}$ As we are maximizing surface mobility with the siloxane backbone, surface reorientation and heterogeneity would be the likely contributors to contact angle hysteresis. Figure 7 depicts the $\Delta \theta$ for PVMS and the three mercaptoalkanol-modified substrates over the ten cycles. The most responsive surface, PVMS-S- $\left(\mathrm{CH}_{2}\right)_{2} \mathrm{OH}$, has the largest observed hysteresis of $\sim 75^{\circ}$, consistent with its repeatable and reversible state between a polar and nonpolar environment. Besides PVMS,

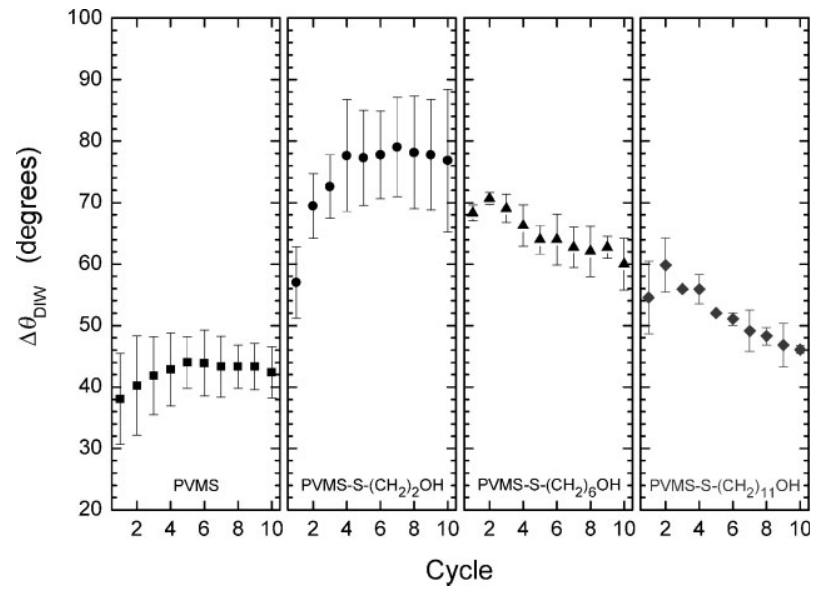

Figure 7. Contact angle hysteresis $\left(\Delta \theta=\theta_{\text {advancing }}-\theta_{\text {receding }}\right)$ for a dynamic contact angle cycle depicted in Figure 5 for: PVMS $(\boldsymbol{\square})$, PVMS-S- $\left(\mathrm{CH}_{2}\right)_{2} \mathrm{OH}$ $(\bullet)$, PVMS-S- $\left(\mathrm{CH}_{2}\right)_{6} \mathrm{OH}(\boldsymbol{\Delta})$, and PVMS-S- $\left(\mathrm{CH}_{2}\right)_{11} \mathrm{OH}(\bullet)$. 
PVMS-S- $\left(\mathrm{CH}_{2}\right)_{11} \mathrm{OH}$ has the smallest hysteresis, continually decreasing with each wet/dry oscillation. This observation is consistent with the notion that we had formed a stable surface in this sample by inducing crystallinity. In the following section, we provide more detailed picture of how chain crystallinity observed in the PVMS-S- $\left(\mathrm{CH}_{2}\right)_{11} \mathrm{OH}$ samples influences chain dynamics on PVMS surfaces.

\subsection{Determination of Semi-Crystallinity}

In addition to the aforementioned differences in wettabilities, we observed visual changes among the samples. Specifically, the PVMS, PVMS-S- $\left(\mathrm{CH}_{2}\right)_{2} \mathrm{OH}$, and PVMS-S- $\left(\mathrm{CH}_{2}\right)_{6} \mathrm{OH}$ specimens were transparent, elastic and tacky; they adhered well to a polystyrene Petri dish. In contrast, the PVMS-S- $\left(\mathrm{CH}_{2}\right)_{11} \mathrm{OH}$ materials were opaque, rigid, and nonadhering to polystyrene (Fig. 8). Upon immersion into hot water (temperature $\geq 70{ }^{\circ} \mathrm{C}$ ), however, PVMS-S- $\left(\mathrm{CH}_{2}\right)_{11}-\mathrm{OH}$ became transparent but turned opaque again upon cooling. The loss of transparency is a classical indicator of semi-crystalline behavior as crystallites impede light propagation through the material.

The opaqueness indicator for the formation of crystalline domains with the $-\mathrm{S}-\left(\mathrm{CH}_{2}\right)_{11} \mathrm{OH}$ modification was also confirmed with optical microscopy at both room temperature and elevated temperature. Specifically, PVMS-S- $\left(\mathrm{CH}_{2}\right)_{11} \mathrm{OH}$ was placed over a transparent printout bearing a sign "NCSU" on a heating stage under the microscope. Heating at a rate of $1{ }^{\circ} \mathrm{C}$ per minute, images $(5 \times$ magnification) were acquired every $30 \mathrm{~s}$ to track the melting temperature transition. Inspection of the images (Fig. 9) indicated this transition occurred between 28 and $32^{\circ} \mathrm{C}$. At elevated temperatures $\left(>45^{\circ} \mathrm{C}\right)$ the letters were clearly visible under the microscope. Upon lowering the temperature, the "NCSU" sign became illegible and almost completely blocked

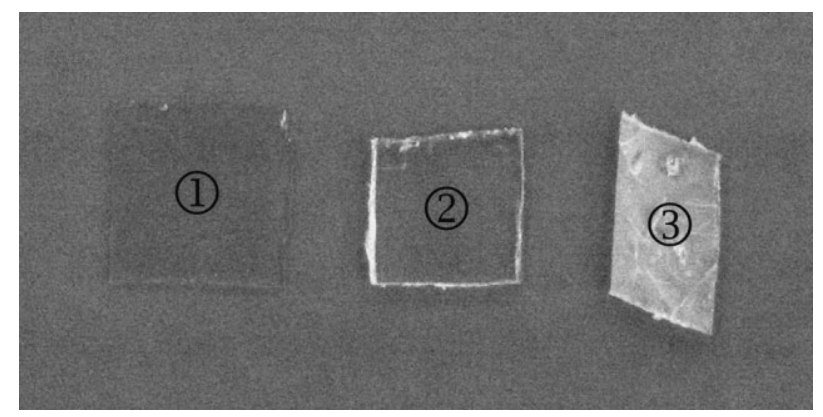

Figure 8. Photographs of mercaptoalkanol-modified PVMS substrates in front of an opaque background; (1) PVMS (2) PVMS-S- $\left(\mathrm{CH}_{2}\right)_{6} \mathrm{OH}$ and (3) PVMS-S- $\left(\mathrm{CH}_{2}\right)_{11} \mathrm{OH}$. The opaqueness of (3) is indicative of crystallites.

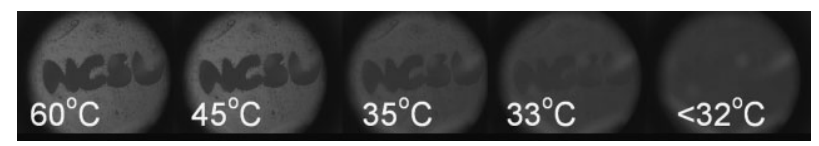

Figure 9. A sample of PVMS-S- $(\mathrm{CH} 2)_{11} \mathrm{OH}$ observed with optical microscopy (at $5 \times$ and in reflectance mode). at temperatures below $32{ }^{\circ} \mathrm{C}$. This experiment was conducted only for illustrative purposes rather that aimed at pinpointing the exact transition temperature. In addition, while the hot stage used for the temperature ramp had poor control below $30^{\circ} \mathrm{C}$, it still demonstrated the substrate's ability to oscillate between either an opaque or transparent state.

In addition to the visual observations, additional experiments were performed on PVMS and the modified substrates ${ }^{[37]}$ to further quantify the temperature transitions including dynamic rheology, DSC, and FTIR-ATR studies. As noted above, it was obvious through sample handling that the PVMS-S- $-\left(\mathrm{CH}_{2}\right)_{11} \mathrm{OH}$ substrate was more rigid than the other modified samples. This observation was further confirmed via dynamic rheology experiments that revealed a ten-fold increase in the storage modulus G' (Fig. 10). Although the modulus did increase, the $\mathrm{G}^{\prime}$ data for PVMS-S- $\left(\mathrm{CH}_{2}\right)_{11} \mathrm{OH}$ is frequency-dependent, indicating an imperfect network (frequency sweep was performed within the linear viscoelastic regime at $0.5 \%$ strain). In contrast, PVMS, PVMS-S- $\left(\mathrm{CH}_{2}\right)_{2} \mathrm{OH}$, and PVMS-S- $(\mathrm{CH} 2)_{6} \mathrm{OH}$ are considered to be nearly perfectly elastic as a zero slope was obtained for the $\mathrm{G}^{\prime}$ versus frequency sweeps, as documented by data shown in Figure 10a. Upon heating semi-crystalline material, ordered polymer chains will relax into their preferred random coil conformations above a melting transition. To determine if this held true for the PVMS-S- $\left(\mathrm{CH}_{2}\right){ }_{11} \mathrm{OH}$ substrate, more detailed analysis of the rheological properties was performed by varying the run temperature for the dynamic frequency sweep tests as shown in Figure $10 \mathrm{~b}$ and c. At an operating temperature of $50{ }^{\circ} \mathrm{C}$, the melting transition (melting point of 11-mercaptoundecanol is between 33 and $\left.37^{\circ} \mathrm{C}\right)^{[38]}$ had been reached in the data in Figure $10 \mathrm{~b}$ as this temperature-induced polymer relaxation state resulted in negligible frequency dependency. This indicated the PVMS-S- $\left(\mathrm{CH}_{2}\right)_{11} \mathrm{OH}$ network had reached near-perfect elasticity. Figure 10c illustrates that upon cooling there is full network recovery as this data replicates those obtained during the run before heating. It thus appears that the ordered alkane chains are

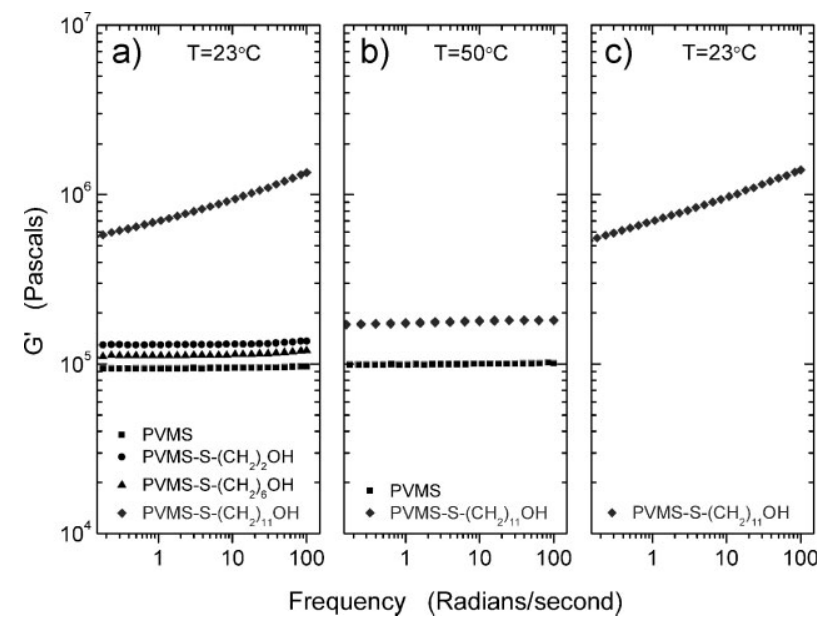

Figure 10. Dynamic rheology on PVMS and mercaptoalkanol-modified PVMS substrates. Runs performed at sequential operational temperatures (T): a) $T=23^{\circ} \mathrm{C}$, b) $T=50^{\circ} \mathrm{C}$, and c) $T=23^{\circ} \mathrm{C}$. The average standard deviation of data is $\pm 33 \mathrm{kPa}$. 
acting as filler-like reinforcers at room temperature, disrupting the elastic nature of the siloxane network.

The $T_{\mathrm{g}}$ is largely due to the intramolecular interactions within the backbone, polarity of the substituents, backbone flexibility, and barriers to rotation. As the bulkiness of the substituents increases, a rise in $T_{\mathrm{g}}$ is typically apparent. The $T_{\mathrm{g}}$ rose remarkably in all three modified samples corresponding to other siloxane polymers that have substituent markedly different from the methyl group as quantified by dynamic scanning calorimetry (Fig. 11). Our modified substrates exhibited an increase in both the chain length and polarity of the silicon vinyl substituent contributing to the higher temperature transitions in comparison to PVMS. Furthermore, the temperature profile for PVMS-S- $\left(\mathrm{CH}_{2}\right)_{11} \mathrm{OH}$ was different than its liquid-like counterparts as a melting transition exists as evident by the distinct endothermic peak of this scan. More detailed analysis of the effect of molecular structure of PVMS and thiol-modified PVMS substrates on $T_{\mathrm{g}}$ and $T_{\mathrm{m}}$ will be presented in a future publication. ${ }^{[39]}$

FTIR-ATR spectroscopy further supported our claim that the 11-mercapto-1-undecanol-modified PVMS surface had undergone a phase transition with the formation of semi-crystalline domains. The data in Figure 12 depict the decrease in frequency shift for both asymmetric and symmetric $\mathrm{C}-\mathrm{H}$ stretches of the methylene group. The characteristic frequency for the $\mathrm{C}-\mathrm{H}$

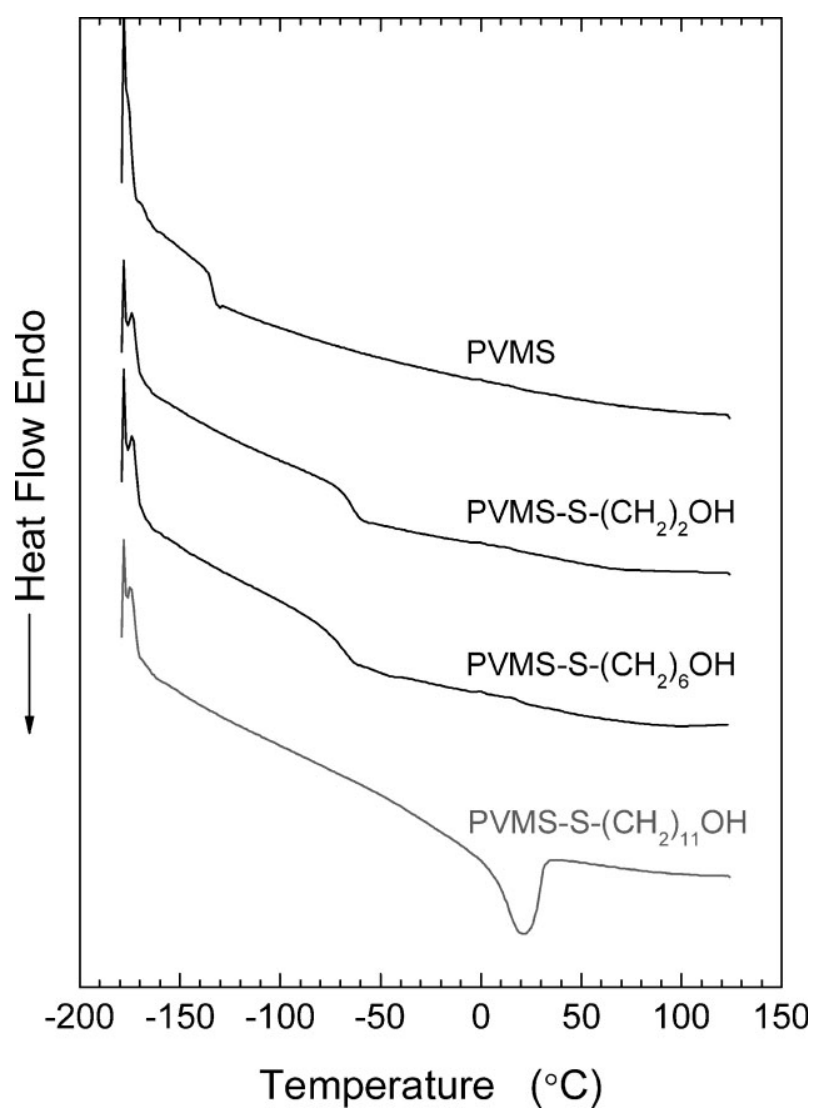

Figure 11. DSC for PVMS and PVMS-modified substrates. The heating rate was $3{ }^{\circ} \mathrm{C} \mathrm{min}-1$, see text for details.

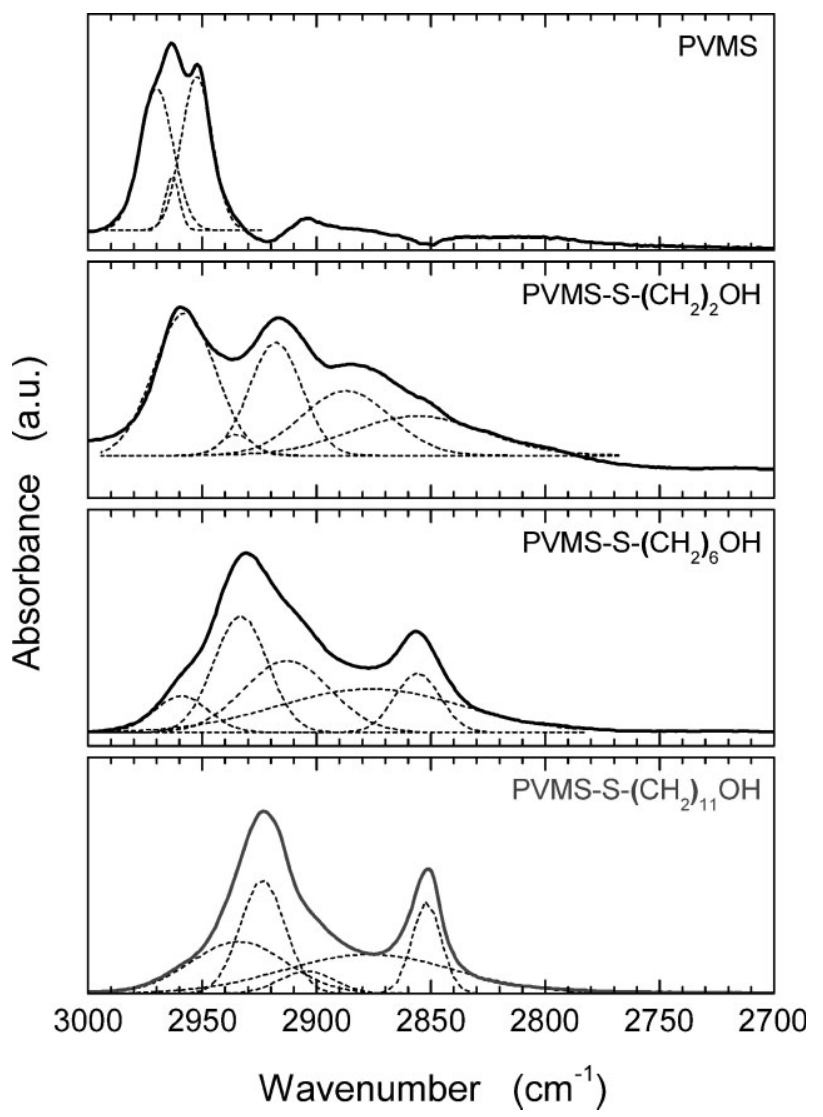

Figure 12. ATR-FTIR data within the methylene stretching region for PVMS and the mercaptoalkanol-modified samples. The resultant chromatogram for each specimen was deconvoluted with multi-peak Guassian fits using OriginLab. The higher wavenumber peak is the characteristic asymmetric methylene stretching vibrations and the lower wavenumber is the characteristic symmetric methylene stretching vibrations. As crystallinity increases, the frequency vibrations shift to lower wavenumbers.

stretching vibrations (asymmetric) occurs at $2920 \mathrm{~cm}^{-1}$ for crystalline polymethylene chains. For the liquid polymethylene state, the $\mathrm{C}-\mathrm{H}$ stretching vibrations (asymmetric) are detected at $2928 \mathrm{~cm}^{-1}$. ${ }^{35]}$ A similar downward shift for the symmetrical $\mathrm{C}-\mathrm{H}$ stretching vibrations is observed for liquid $\left(2856 \mathrm{~cm}^{-1}\right)$ to crystalline $\left(2850 \mathrm{~cm}^{-1}\right)$ transition of the polymethylene chain. ${ }^{[35]}$ Our results for the modified PVMS substrates reveal that while the $-\mathrm{S}-\left(\mathrm{CH}_{2}\right)_{6} \mathrm{OH}$ substituted surface is in a liquid-like state, the $-\mathrm{S}-\left(\mathrm{CH}_{2}\right)_{11} \mathrm{OH}$ group is in a crystalline-like state. Our observed frequency shifts between these two substrates agree closely with the reported polymethylene transition. Our results are also in accord with those of Chaudhury and Owen, ${ }^{[34]}$ who showed that adhesion hysteresis can be tuned by varying the surface density of hexadecyltrichlorosilane (HTS) chemisorbed films on PDMS. Highly packed films of HTS were found to be crystalline $\left(v_{\mathrm{a}}\left(\mathrm{CH}_{2}\right)=2919 \mathrm{~cm}^{-1}\right.$ and $\left.v_{\mathrm{s}}\left(\mathrm{CH}_{2}\right)=2850 \mathrm{~cm}^{-1}\right)$ with high adhesion hysteresis. The opposite was true for a less dense film of HTS. From all the evidence presented, we infer that after the first wet-dry cycle, $-\mathrm{S}-\left(\mathrm{CH}_{2}\right)_{11} \mathrm{OH}$ groups were trapped just beneath the surface in a semi-crystalline structure, formed presumably via van der Waals interactions acting among 


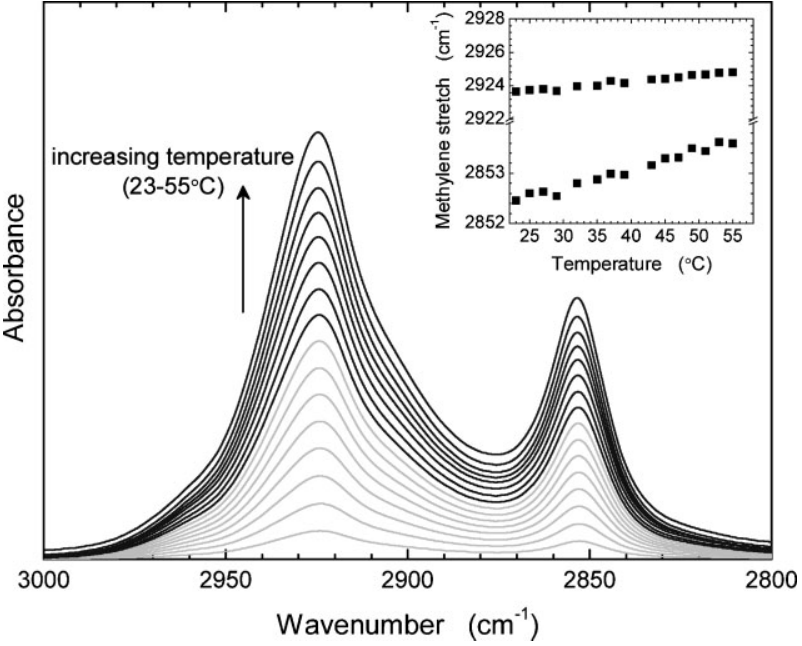

Figure 13. ATR-FTIR data recorded within temperature range of $23-55^{\circ} \mathrm{C}$ for PVMS-S- $\left(\mathrm{CH}_{2}\right)_{11} \mathrm{OH}$. As the temperature increases the material transitions through a melting region and loses some crystallinity. This is reflected in an upward frequency shift for the characteristic asymmetric and symmetric methylene stretching vibrations with increasing temperature (see inset). The light and dark lines represent the measurements below and above the melting temperature $\left(T_{m}\right)$ of $\mathrm{HS}-\left(\mathrm{CH}_{2}\right)_{11} \mathrm{OH}$, respectively $\left(T_{\mathrm{m}}=35^{\circ} \mathrm{C}\right)$.

neighboring - $\left(\mathrm{CH}_{2}\right)_{11}$ - chains, and did not respond to the presence of water on the surface. Annealing the sample appeared to partially "melt" the semi-crystalline regions as the substrate became transparent, hence allowing the mercaptododecanol sidechains to reconstruct moderately at the surface.

As we detected the melting transition for PVMS-S- $\left(\mathrm{CH}_{2}\right)_{11} \mathrm{OH}$ both visually and with dynamic rheology, we expected that FTIR-ATR studies performed at elevated temperatures would result in $\mathrm{C}-\mathrm{H}$ stretching vibrations characteristic of a liquid-like state. The data in Figure 13 illustrate this behavior. We heated PVMS-S- $\left(\mathrm{CH}_{2}\right)_{11} \mathrm{OH}$ from room temperature to $55^{\circ} \mathrm{C}$. At each step interval, the temperature was held constant during the course of the FTIR scan. The inset of Figure 13 depicts a steady increase in the methylene stretching vibrations as the temperature is ramped, confirming a reduction in the amount of crystallinity in the probed sample. At this point, we cannot comment on why there is no sharp transition between the liquidlike and semi-crystalline-like conformations of the chains.

\section{Conclusion}

We summarize by emphasizing several key points of the novel design of our surfaces. They represent the only known polymeric system we are aware of that responds almost instantaneously to wettability changes at room temperature $\left(\Delta \theta \approx 2^{\circ} \quad \mathrm{s}^{-1}\right.$ for PVMS-S- $\left.\left(\mathrm{CH}_{2}\right)_{2} \mathrm{OH}\right)$. This behavior results from the high flexibility of the siloxane backbone and the large disparity of surface energies between the hydrophobic methyl and the hydrophilic mercaptoalkanol side chains. The response rate depends on the number of methylene spacers in the mercaptoalkanol. While for $n=2$ and 6 , the surface reconstructs almost instantaneously, $n=11$ specimens resist reconstruction because of strong vander Waals forces leading to the formation of semicrystalline regions. We have shown that liquid-like siloxane surfaces ( $n=2$ and 6) can be continually oscillated between polar and nonpolar states for at least ten cycles, with no loss of wettability for the 3-mercaptopropanol modified substrate. We confirmed the formation of semi-crystalline regions in PVMS-S- $\left(\mathrm{CH}_{2}\right)_{11} \mathrm{OH}$ substrates through dynamic rheology, DSC, and FTIR-ATR. The analysis revealed a melting transition in PVMS-S- $\left(\mathrm{CH}_{2}\right)_{11} \mathrm{OH}$ that was absent in PVMS-S- $\left(\mathrm{CH}_{2}\right)_{2} \mathrm{OH}$ and PVMS-S- $\left(\mathrm{CH}_{2}\right)_{6} \mathrm{OH}$.

\section{Experimental}

PVMS Synthesis: Hydroxy-terminated PVMS was synthesized using the methodology described elsewhere [20]. Molecular weights and polydispersity indices (ranging between 4.9-78.7 and 1.5-3.0 kDa, respectively) were determined using size exclusion chromatography (SEC) with HPLCgrade toluene as a mobile phase. The SEC system was equipped with three Styragel $4.6 \times 300 \mathrm{~mm}$ columns (models HR3, HR4, and HR4E, Waters Corporation, Milford, MA) for the polymer separation. The Optilab rEX (refractometer with EXtended range, Wyatt Technology, Santa Barbara, CA) was used as the concentration detector and a miniDAWN Tristar as the light scattering detector (Model WTR-02, Wyatt Technology, Santa Barbara, CA). With the intensity of light scattered and the absolute concentration measured, the molar mass is obtained. Polymer solutions with concentration of $\approx 2 \mathrm{mg} \mathrm{mL}^{-1}$ were prepared. The solutions were filtered to SEC sampling vials with $0.2 \mu \mathrm{m}$ PTFE syringe filters. The SEC data was processed with ASTRA software (version 5.1.9.1, Wyatt Technology, Santa Barbara, CA). The dn/dc of PVMS was determined by preparing exact solutions with concentrations ranging from $0-2.5 \mathrm{mg} \mathrm{mL}^{-1}$ of polymer in HPLC-grade toluene; two different batches of PVMS were selected for testing with the refractometer. The $\mathrm{dn} / \mathrm{dc}$ value is represented by the slope of the DRI versus concentration, as shown in Figure S1 in the Supporting Information. As there appears to be a slight molecular weight dependence on the $\mathrm{dn} / \mathrm{dc}$ value, samples were analyzed as deemed appropriate in ASTRA. An example PVMS run with changing molecular weights is shown in Figure S2 in the Supporting Information, where the final molecular weight of the polymer was determined to be $\sim 45 \mathrm{kDa}$ after $6 \mathrm{~h}$ at $\sim 110^{\circ} \mathrm{C}$ (Table S1 of the Supporting Information). The kinetics of the reaction depends on the lithium hydroxide concentration and activity as well as the starting material (Dow Corning PJ Fluid) quality. Light scattering indicates a higher molecular weight peak in the final sample; this is a signature of an agglomerate/gel that occurs with long reactions times and does not contribute greatly to an overall higher molecular weight as the reaction rates slow down with time.

PVMS Network Formation: Chemical crosslinking of siloxanes can be accomplished with four types of common commercial reactions $[40,41]$ : i) peroxide-induced free radical, ii) condensation reactions, iii) hydrosilylation addition reactions, and iv) hydridosilane/silanol reactions. In order to gain control over the cross-link densities and preserve the active vinyl group along the PVMS backbone, we utilize the condensation (or alkoxy-cure) reaction route that entails linking hydroxyl-terminated siloxanes with tetraethoxysilane (TEOS) in the presence of tin catalyst. This procedure results in a model tetrafunctional network, where the "liquid" nature of the siloxane backbone between junction points remains intact [42]. Our PVMS networks were formulated as previously described with the $36.3 \mathrm{kDa}\left(M_{\mathrm{w}} /\right.$ $M_{\mathrm{n}}=2.25$ ) polymer [20]. In addition, PDMS networks were prepared by cross-linking monodisperse PDMS chains by following reported procedures $[42,43]$ and by utilizing the commercial Sylgard-184 kit (Dow Corning). All other chemicals were obtained from Sigma-Aldrich Chemicals and used as received.

Thiol-ene Modification of PVMS Networks: The storage modulus (G') of elastomeric PVMS networks measured using the methods described below was found to be $\sim 8 \times 10^{4} \mathrm{~Pa}$ after Soxhlet extraction using toluene for at 
least $48 \mathrm{~h}$ followed by drying at $75^{\circ} \mathrm{C}$ under $30-\mathrm{mm} \mathrm{Hg}$ vacuum. The vinyl moieties on PVMS were subsequently saturated via azodiizobutyronitrile (AIBN)-initiated thiol-ene radical addition of $\mathrm{HS}\left(\mathrm{CH}_{2}\right)_{n} \mathrm{OH}(n=2,6$, and 11)[44]. After the reaction, the samples (denoted as PVMS-S- $\left(\mathrm{CH}_{2}\right)_{n} \mathrm{OH}$ ) were re-extracted, dried, and stored in a low-humidity chamber. Experiments using IR spectroscopy confirmed that the grafting density of $-\mathrm{S}\left(\mathrm{CH}_{2}\right)_{n} \mathrm{OH}$ was approximately equal in each sample. In a typical thiolene addition reaction approximately $0.12 \mathrm{~g}$ of the extracted and dried PVMS network was placed at the bottom of a reaction flask. The sample was allowed to swell in $10 \mathrm{~g}$ of $\mathrm{N}_{2}$-purged toluene overnight. A mixture of 1dodecanethiol $(0.22 \mathrm{~g})$ and AIBN $(0.0048 \mathrm{~g})$ was purged with nitrogen and added to the reaction flask. The flask was capped and heated to $60^{\circ} \mathrm{C}$ for 5-6h. The PVMS-modified sample was removed from the flask then extracted in toluene for $48 \mathrm{~h}$. After extraction the substrate was dried under $25 \mathrm{~mm} \mathrm{Hg}$ vacuum at $70^{\circ} \mathrm{C}$ for 1 day. The sample was stored in a desiccator until testing was performed. Substrates similarly modified with 3 . mercaptopropionic acid were extracted in DI water, dried with nitrogen, and immediately tested for wettability.

Surface Reorientation: Organization of the thiol-based moieties on the PVMS surfaces were assessed via static contact angle (SCA) and dynamic contact angle (DCA) measurements using DI water $(R>15 \mathrm{M} \Omega \mathrm{cm})$. In a typical SCA experiment (sessile drop technique) experiments were performed with using a Ramé-Hart contact angle goniometer (mode 100-00) equipped with a CCD camera, and analyzed with the Ramé-Hart Imaging 2001 software. The contact angles $\theta$ were recorded as a function of time (with $5 \mathrm{~s}$ increments for $5 \mathrm{~min}$ ) after depositing $8 \mu \mathrm{L}$ of the probe liquid on the substrate (the error in $\theta= \pm 1.5^{\circ}$ ). The principle of DCA experiments is shown schematically in Figure S3 of the Supporting Information. Each cycle consisted of placing a nitrogen-purged rectangular $\left(\sim 10 \times 10 \times 1 \mathrm{~mm}^{3}\right)$ PVMS slab above a beaker containing DI water at room temperature (Stage 1). The DCA stage was raised at a rate of $80 \mu \mathrm{m} \mathrm{s}^{-1}$ until the detection of the water-substrate interface (Stage 2). At that point, the stage was advanced for $3 \mathrm{~mm}$, held for $8.5 \mathrm{~min}$ (Stage 3), and returned to its original position. The total water contact time was 9 min for each cycle. During each cycle, the DCA recorded the total force acting on the sample $\left(F_{\mathrm{t}}\right) . F_{\mathrm{t}}$ is related to contact angle through:

$F_{\mathrm{t}}=\mathrm{mg}-V_{\mathrm{s}} \rho_{\mathrm{L}} \mathrm{g}+P \gamma_{\mathrm{L}} \cos (\theta)$

where $\mathrm{mg}$ is the gravitational force zeroed out by taring the balance prior to the cycle run, $V_{\mathrm{s}}$ the volume of the solid immersed in water, $\rho_{\mathrm{L}}$ the DI water density, $P$ the wetted sample perimeter, and $\gamma_{L}$ is the surface tension of $D I$ water. This technique facilitates measurement of advancing and receding contact angles as well as the change in contact angle during the sample hold-time. Since the immersed volume of the sample $\left(V_{s}\right)$ remains constant during the hold-time, only the wetting force, $P \gamma_{L} \cos (\theta)$, changes as a function of time due to the surface reconstruction. After the completion of each cycle, the sample was blow-dried with nitrogen gas and another cycle was commenced. The lapse time between two consecutive cycles was $\sim 7 \mathrm{~min}$; ten wettability cycles were carried out for each sample.

Infrared Spectroscopy: FTIR-ATR was used to characterize chemical changes that took place on the modified PVMS surface. All spectra were collected using a BioRad/Digilab FTS-3000 FT-IR spectrometer using a mounted crystalline Ge, ATR sampling attachment (Pike Technologies inc., MIRacle Single Reflection ATR) with a normal spectral response of 650 to $5500 \mathrm{~cm}^{-1}$. The infrared light was focused onto the photodiode of a liquid nitrogen-cooled, wide band mercury-cadmium-telluride (MCT) detector with a normal spectral response of 650 to $7000 \mathrm{~cm}^{-1}$. There is nominally one reflection with a spot size of approximately $100 \mu \mathrm{m}$. The spectrometer and attachment were purged with dry compressed air, which reduces the possibility of atmospheric water or $\mathrm{CO}_{2}$ contamination of the spectra and samples. For each sample, 64 scans ( 10 repeats per sample) were collected using Ge-crystal detector with a resolution of $2 \mathrm{~cm}^{-1}$ under constant nitrogen flux to eliminate the effect of water vapor on the collected data. The data were analyzed using BioRad-IR software. In addition the ATR element was fitted with a Peltier thermal heating and cooling chip allowing for temperature control of the samples $\left( \pm 70^{\circ} \mathrm{C}\right.$ above ambient). The spectra presented are an average of 1 accumulation of 64 scans. Sample spectra were recorded over a temperature range from ambient to $50 \pm 0.5^{\circ} \mathrm{C}$ in $1-5^{\circ} \mathrm{C}$ steps, with a resolution of $2 \mathrm{~cm}^{-1}$. The spectra were converted into absorbance units by taking the negative of the log ratio of a sample spectrum to that of an air spectrum. The data were then transferred to data processing software (Microcal Origin, Microcal Software Inc. Northampton, MA), where numerical treatment and final graphs were prepared.

Differential Scanning Calorimetry: DSC was performed using a TA Instrument Q100. Two runs were carried out for each sample in the range of -80 to $130^{\circ} \mathrm{C}$ with a heating rate of $3^{\circ} \mathrm{C} \mathrm{min}^{-1}$ under a nitrogen atmosphere. The $T_{\mathrm{g}}$ values were determined as the onset points from the second scans if applicable. The melting point $T_{m}$ was taken as the maximum of the endothermic peak.

Dynamic Rheology: Dynamic frequency sweeps were performed under isothermal conditions from 0.05 to $100 \mathrm{rad} \mathrm{s}^{-1}$ on a Rheometrics Advanced Rheometric Expansion System (ARES) with a defined strain within the linear viscoelastic regime using a parallel plate geometry. Wall slip was minimized my applying a normal force for optimum plate contact producing repeatable results.

\section{Acknowledgements}

This research was supported by the Office of Naval Research, Grant no. N00014-08-1-0369. We thank Dr. Simon Lappi for assisting with the temperature-dependent IR experiments, Prof. Dr. Saad Khan for access to the ARES rheometer, and Prof. Dr. Maurice Balik for use of the differentia scanning calorimetry set up. Supporting Information is available online from Wiley InterScience or from the author.

Received: May 4, 2008

Revised: June 30, 2008

Published online:

[1] I. Luzinov, S. Minko, V. V. Tsukruk, Prog. Polym. Sci. 2005, 29, 635.

[2] T. P. Russell, Science 2002, 297, 964

[3] S. Dai, P. Ravi, K. C. Tam, Soft Matter 2008, 4, 435.

[4] W. H. La, R. M. Wang, Y. F. He, H. F. Zhang, Prog. Chem. 2008, $20,351$.

[5] I. Luzinov, S. Minko, V. V. Tsukruk, Soft Matter 2008, 4, 714.

[6] S. Minko, Prog. Chem. 2006, 46, 397.

[7] I. Y. Galaev, B. Mattiasson, Trends Biotechnol. 1999, 17, 335

[8] C. J. T. Ellison, J. M. Torkelson, Nat. Mater. 2003, 2, 695.

[9] A. D. Schwab, D. M. G. Agra, J. H. Kim, S. Kumar, A. Dhinojwala, Macromolecules 2000, 33, 4903.

[10] W. E. Wallace, D. A. Fischer, K. Efimenko, W. L. Wu, J. Genzer, Macromolecules 2001, 34, 5081

[11] S. R. Holmes-Farley, R. H. Reamey, R. Nuzzo, T. J. McCarthy, G. M. Whitesides, Langmuir 1987, 3, 799.

[12] J. T. Koberstein, J. Polym. Sci. Part B: Polym. Phys. 2004, 42, 2942.

[13] D. H. Carey, G. S. Ferguson, Macromolecules 1994, 27, 7254

[14] D. H. Carey, G. S. Ferguson, J. Am. Chem. Soc. 1996, 118, 9780.

[15] D. H. Carey, S. J. Grunzinger, G. S. Ferguson, Macromolecules 2000, 33 8802.

[16] J. Genzer, K. Efimenko, Science 2000, 290, 2130.

[17] J. H. Rouse, P. L. Twaddle, G. S. Ferguson, Macromolecules 1999, 32, 1665

[18] K. Efimenko, J. Genzer, Mater. Res. Soc. Sym. Proceed. 2002, DD10.3.1, 710.

[19] C. D. Bain, G. M. Whitesides, J. Am. Chem. Soc. 1988, 110, 5897.

[20] K. Efimenko, J. A. Crowe, E. Manias, D. W. Schwark, D. A. Fischer, J. Genzer, Polymer 2005, 46, 9329.

[21] J. A. Crowe, J. Genzer, J. Am. Chem. Soc. 2005, 127, 17610.

[22] J. Chojnowski, M. Cypryk, W. Fortuniak, M. Scibiorek, K. Rozga-Wijas, Macromolecules 2003, 36, 3890

[23] K. RozgaWijas, J. Chojnowski, S. Boileau, J. Polym. Sci. Pol. Chem. 1997, 35, 879. 
[24] K. RozgaWijas, J. Chojnowski, T. Zundel, S. Boileau, Macromolecules 1996, 29, 2711.

[25] S. J. Grunzinger, G. S. Ferguson, J. Am. Chem. Soc. 2001, 123, 12927.

[26] S. Khongtong, G. S. Ferguson, J. Am. Chem. Soc. 2001, 123, 3588.

[27] S. Khongtong, G. S. Ferguson, J. Am. Chem. Soc. 2002, 124, 7254.

[28] J. A. Crowe, K. Efimenko, J. Genzer, D. W. Schwark in Responsive Polymer Materials: Design and Applications, (Ed.: S. Minko), Blackwell Publishing, Ames, IA 2006, pp. 184.

[29] D. Wong, C. Jalbert, J. T. Koberstein, Polymer Prepr. 1998, 39, 901.

[30] S. H. Anastasiadis, H. Retsos, S. Pispas, N. Hadjichristidis, S. Neophytides, Macromolecules 2003, 36, 1994.

[31] S. R. Holmesfarley, C. D. Bain, G. M. Whitesides, Langmuir 1988, 4, 921.

[32] S. R. Holmesfarley, R. H. Reamey, T. J. McCarthy, J. Deutch, G. M. Whitesides, Langmuir 1985, 1, 725.

[33] D. L. Allara, A. N. Parikh, E. Judge, J. Chem. Phys. 1994, 100, 1767.

[34] M. K. Chaudhury, M. J. Owen, J. Phys. Chem. 1993, 97, 5722.

[35] R. G. Snyder, H. L. Strauss, C. A. Elliger, J. Phys. Chem. 1982, 90, 5623.
[36] J. Andrade, Surface and Interfacial Aspects of Biomedical Polymers, Plenum Press, New York 1985.

[37] J. A. Crowe, K. Efimenko, J. Genzer, in: Science and Technology of Silicones and Silicone-Modified Materials, (Ed: S. J. Clarson), American Chemical Society, Washington 2006.

[38] (11-Mercapto-1-undecanol) 97\%; http://www.sigmaaldrich.com/catalog/ search/ProductDetail/ALDRICH/447528, accessed November 2008.

[39] J. A. Crowe-Willoughby, D. Stevens, L. C. Clarke, J. Genzer, unpublished.

[40] S. J. Clarson, Siloxane Polymers, (Eds.: S. J. Clarson, J. A. Semlyen), PTR Prentice Hall, Englewood Cliffs, New Jersey 1993, pp. 216.

[41] S. J. Clarson, in: Siloxane Polymers, (Eds.: S. J. Clarson, J. A. Semlyen), PTR Prentice Hall, Englewood Cliffs, New Jersey 1993, pp. 567.

[42] S. J. Clarson, in: Silicon-Containing Polymers, (Eds.: R. J. Jones, W. Ando, J. Chojnowski), Kluwar Academic Publishers, Dordrecht 2000, pp. 185.

[43] K. Efimenko, W. E. Wallace, J. Genzer, J. Colloid Interface Sci. 2002, 254, 306.

[44] L. Herczynska, L. Lestel, S. Boileau, J. Chojnowski, S. Polowinski, Eur. Polym. J. 1999, 35, 1115. 